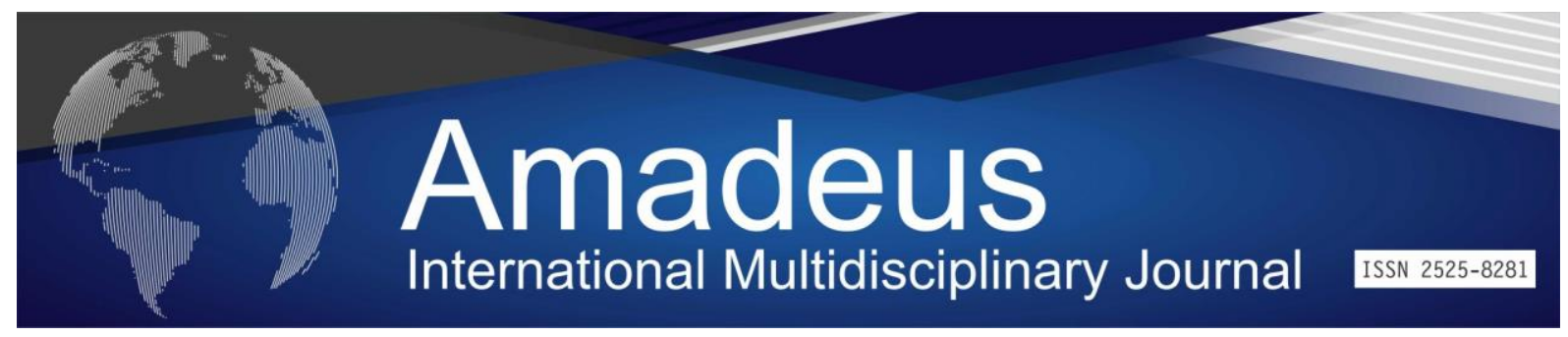

DOI: 10.14295/aimj.v5i9.145

\title{
Child Bedtime History for Grown Up People: Race, Racism and Power in Brazilian History
}

Lousana de Jesus Santana Marcelo Máximo Purificação ${ }^{2}$ Elisângela Maura Catarino ${ }^{3}$ Denilra Mendes Ferreira ${ }^{4}$ Akira de Alencar Borges Bessa $^{5}$

\begin{abstract}
The history of blacks in Brazil is "a story to rock great people" as it is referred to by the 2019 plot of the Samba School Estação Primeira de Mangueira. Seen and told from the historical perspective and the interest of a layer of society, when we hear the history of black people in Brazil, we understand the dangers and the contours of a "unique history". When we try to strip the lines of this story, we understand the strength, the weight and the power of the expression "Brazilian racism". This study is characterized as bibliographic, developed from reading reviews. It aims to provoke a discussion about race, racism and power relations in Brazil.
\end{abstract}

Keywords: Race; Racism; Power.

\section{"História pra Ninar Gente Grande": Raça, Racismo e Poder na História do Brasil}

Resumo: A história do negro no Brasil é "história para ninar gente grande" como a ela se refere o enredo de 2019 da Escola de Samba Estação Primeira de Mangueira. Vista e contada a partir da perspectiva histórica e do interesse de uma camada da sociedade, quando ouvimos a história do negro no Brasil compreendemos os perigos e os contornos de uma "história única". Quando buscamos desnudar as entrelinhas dessa história, compreendemos a força, o peso e o poder da expressão "racismo à brasileira". Este estudo, caracteriza-se como bibliográfico, desenvolvido a partir de revisão de leituras. Objetiva provocar uma discussão acerca da raça, racismo e relações de poder no Brasil.

Palavras chave: Raça; Racismo; Poder.

\footnotetext{
${ }^{1}$ Graduada em Pedagogia Licenciatura Plena pelo Departamento de Educação do Campus XV da Universidade do Estado da Bahia. Mestrado Profissional em Intervenção Educativa e Social (MPIES) Linha 2: Novas formas de subjetivação e organização comunitária, na Universidade do Estado da Bahia (UNEB), Departamento de Educação (DEDC) do Campus XI - Serrinha-Ba. E-mail: lousanasantana@gmail.com

${ }^{2}$ Pós-Doutor em Educação pela Universidade de Coimbra - UC/Pt. Doutor em Ciências da Religião pela PUC-Goiás. Professor Titular na Fundação Integrada Municipal de Ensino Superior - FIMES/UNIFIMES. Professor permanente do Mestrado Profissional em Intervenção Educativa e Social (MPIES), Departamento de Educação (DEDC) do Campus XI - Serrinha - Ba. E-mail: maximo@ unifimes.edu.br

${ }^{3}$ Doutora em Ciências da Religião pela PUC-Goiás, Doutoranda em Educação pela Universidade Luterana do Brasil (ULBRA). Professora Titular na Fundação Integrada Municipal de Ensino Superior - FIMES/UNIFIMES. E-mail: maura@ unifimes.edu.br

${ }^{4}$ Graduada em Pedagogia (Licenciatura) pela Universidade Estadual Vale do Acaraú (2007). Mestranda em Educação pela Universidade Luterana do Brasil - ULBRA. Servidora do Instituto Federal do Maranhão - IFMA. E-mail: denilra@ifma.edu.br

${ }^{5}$ Graduada em História pela Universidade Católica de Goiás (2002). (ENEM). Mestranda em Educação no Programa de Pós-Graduação em Educação - Mestrado Acadêmico da Faculdade de Inhumas - FacMais. Professora P-IV na SEDUC - GO, desde 2012. E-
} mail:akira@aluno.facmais.edu.br 


\section{Introdução}

Este artigo tem o objetivo de discorrer acerca das relações racistas presentes no Brasil e como essas relações reverberam na narrativa histórica de povos subalternizados, dando ênfase nas relações raciais. Para alcançar tal objetivo, foi utilizada como metodologia a pesquisa bibliográfica.

O título deste artigo faz alusão ao samba de enredo da escola de samba Estação Primeira de Mangueira do ano 2019, que teve como proposta trazer à tona as entrelinhas da história do Brasil e através do qual se busca "contar a história que a história não conta, o avesso do mesmo lugar" (Escola de Samba Mangueira). A escola de samba foi campeã com o enredo do mesmo nome, naquele ano, no Rio de Janeiro.

A construção nacional da ideia do lugar do negro, desde a independência do Brasil e a "venda" da imagem de uma suposta democracia racial manteve os privilégios e a supremacia da "raça" branca sobre a negra. As narrativas contadas para a manutenção da supremacia branca e a subordinação negra desvendam uma construção ideológica que naturaliza as relações de desigualdades e hierarquização entre os grupos. As narrativas históricas cuidadosamente articuladas promovem dentro dos grupos subalternizados a interiorização através de mecanismos de poder, tais como escolas, leis, contratos sociais, mídia, relação de trabalho etc.

Para discutir a temática proposta, o texto é dividido em três tópicos. O primeiro, Raça racismo e etnia, discorre acerca dos termos que o compõem e traz a perspectiva histórica do uso do termo "raça". No segundo tópico, Racismo no Brasil, é discutido o racismo dissimulado presente no país, escondido por trás de uma ideologia que atende o status quo. $\mathrm{O}$ terceiro tópico, denominado $O$ poder de contar a história, discorre sobre a relação de poder sobre grupos a partir de uma única narrativa legitimada por vias institucionais.

\section{Raça, racismo e etnia: três fios de uma mesma realidade}

Nessa seção partimos por conceituar os termos raça, etnia e racismo, utilizando para isso, o dicionário de Língua Portuguesa Priberam (https://dicionario.priberam.org/), de domínio público, onde consta: 


\section{Ra·ça}

(italiano razza)

substantivo feminino

1. Divisão tradicional de indivíduos cujos caracteres físicos biológicos são constantes e hereditários (ex.: raça amarela, raça branca, raça negra, raça vermelha). [Os progressos da genética levam hoje a rejeitar qualquer tentativa de classificação racial. ] 2. Subdivisão de uma espécie animal (ex.: raças bovinas; raça de cães).

3. Conjunto de ascendentes e descendentes de uma família, um povo; geração. = DESCENDÊNCIA, ESTIRPE, FAMÍLIA, GERAÇÃO, LINHAGEM

4. Conjunto de pessoas da mesma profissão, das mesmas tendências (ex.: raça dos poetas).

5. [Figurado] Conjunto de indivíduos ou coisas da mesma qualidade. = CASTA, CLASSE, ESPÉCIE, JAEZ, LAIA, TIPO

\section{et $\cdot \mathbf{n i} \cdot \mathbf{a}$}

(grego ethnos, povo + -ia)

substantivo feminino

Agrupamento de famílias numa área geográfica cuja unidade se assenta numa estrutura familiar, econômica e social comum e numa cultura comum.

\section{ra· $\operatorname{cis} \cdot \mathbf{m o}$}

$($ raça $+-i s m o)$

substantivo masculino

1. Teoria que defende a superioridade de um grupo sobre outros, baseada num conceito de raça, preconizando, particularmente, a separação destes dentro de um país (segregação racial) ou mesmo visando o extermínio de uma minoria.

2. Atitude hostil ou discriminatória em relação a um grupo de pessoas com características diferentes, notadamente etnia, religião, cultura, etc. (PRIBERAM, acesso em 11 fev. 2020).

Diante das definições acima mencionadas, podemos perceber que o termo raça está mais ligado a questões biológicas no primeiro e segundo sentidos, evoluindo, depois, para sentidos com aproximações à definição de etnia. Como racismo o dicionário online define as atitudes hostis tanto ligadas à raça quanto à etnia. Os termos anteriormente definidos pelo dicionário online Priberam fazem alusão a diferenças existentes tanto no âmbito biológico quanto no âmbito cultural, religioso, de territorialidade etc. Diante de um emaranhado de definições Almeida (2019) discorre a respeito dizendo:

Raça não é um termo fixo, estático. Seu sentido está inevitavelmente atrelado às circunstâncias históricas em que é utilizado. Por trás da raça sempre há contingências, conflitos, poder e decisão, de tal sorte que se trata de um conceito relacional e histórico. Assim, a história da raça ou das raças é a história da construção política e económica (Almeida, 2019, p. 24 e 25. Grifos do autor).

Embora Almeida considere a divisão da humanidade em raças uma criação da modernidade, é interessante a forma como ele aborda que tal conceito é adaptável às nuances 
no lócus onde ele se desenvolve. Atualmente podemos perceber que historicamente o conceito de raça é aplicado de formas diferentes e o racismo que hierarquiza tem tons diferenciados dependendo de onde ocorre.

Pode-se notar que a forma de racismo que ocorria na antiguidade tinha, inicialmente, um embasamento religioso e filosófico fundamentado no estranhamento a partir do fenótipo e, posteriormente, ganha bases científicas, após a descoberta do Novo Mundo, quando então se intensifica o racismo científico/biológico. Tanto na antiguidade como na modernidade o objetivo do racismo é o mesmo: a destruição total ou parcial de raças tidas como inferiores.

O espírito positivista do século XIX transformou as indagações sobre as diferenças humanas em indagações científicas, de tal sorte que de objeto filosófico, o homem passou a ser objeto científico. A biologia e a física serviram com modelos explicativos da diversidade humana: nasce a ideia de que características biológicas - determinismo biológico - ou condições climáticas e/ou ambientais - determinismo geográfico - seriam capazes de explicar as diferenças morais, psicológicas e intelectuais entre as diferentes raças. Desse modo, a pele não branca e o clima tropical favorecem o surgimento de comportamentos imorais, lascivos e violentos, além de indicarem pouca inteligência. Por essa razão, Arthur de Gobineau recomendou evitar a 'mistura de raças', pois o mestiço tendia a ser o mais 'degenerado' (Almeida, 2019, p. 29. Grifos do autor.)

$\mathrm{Na}$ fala de Almeida (2019) podemos notar que, em muitos aspectos, o Brasil se encaixa nas características acima mencionadas, sendo nosso país, a partir do descrito, um lugar de degenerados, já que a população de negros e nativos era muito grande além das questões climáticas que influenciavam diretamente na sua proliferação.

\section{O olhar de quem olha e o olhar de quem é olhado - Racismo no Brasil}

A história do Brasil é cheia de nuances narradas em fatos, carregada dos perigos de uma história única, transcrita a partir do olhar do colonizador, suprimindo em muitos contextos, a voz (a fala) e o olhar das minorias. 22 de abril de 1500 é o suposto dia do descobrimento do Brasil e o início de um processo de expansão dessa porção da América semelhante às ocorridas em outras partes deste continente. Também no Brasil a exploração de mão de obra para a extração de riquezas naturais iniciou-se pelos próprios nativos. Com o tempo, a quantidade da população indígena foi reduzida por conta de doenças e do processo 
de resistência (fugas e lutas) dos índios ao processo de desumanização imposto pelos invasores. (Munanga \& Gomes, 2016, p.16)

A escravidão indígena foi substituída pelo lucrativo sistema escravista dos negros africanos, modalidade de escravidão que, além de proporcionar, em tese, um trabalhador mais resistente, ainda movimentava o tráfico que oferecia lucro à Europa. No Brasil, o tráfico negreiro resultou na vinda de um número em torno de 3.650 .000 pessoas que teriam como destino o trabalho forçado em lavouras de cana de açúcar, fumo, algodão, café e posteriormente - nas minas. O espaço social do negro no Brasil era o lugar de subalternos, sendo eles impedidos de acesso ao que hoje definimos como direitos básicos, tais como educação, saúde, moradia, emprego, lazer e igualdade. O negro trazido para o Brasil foi colocado na categoria de propriedade.

Diante de um longo período de desumanização, o pós-abolição não representou, necessariamente, liberdade e presságio de dias melhores para a população negra do Brasil, visto que tal população já havia passado por 300 anos de segregação. Objetificados durante os 300 anos e considerados passíveis de serem vendidos e armazenados pelos seus senhores, os negros - após alcançarem o status de pessoas - continuaram a ser discriminados negativamente pela sociedade brasileira.

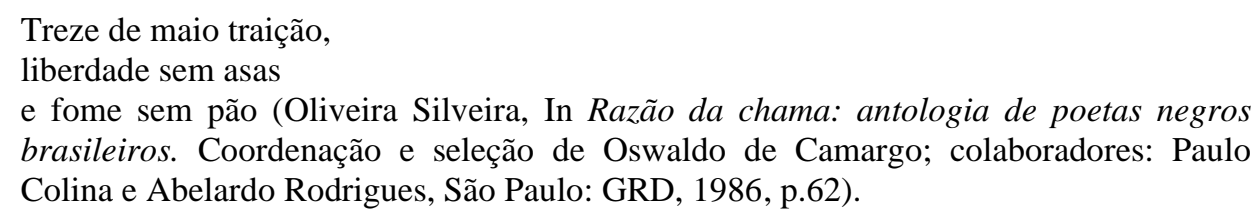
brasileiros. Coordenação e seleção de Oswaldo de Camargo; colaboradores: Paulo Colina e Abelardo Rodrigues, São Paulo: GRD, 1986, p.62).

Mesmo diante de tais evidências da existência do racismo no Brasil, foi difundido, pela elite científica nacional e internacional que o país - mesmo tendo passado por um trajeto onde se firmou a exploração do negro e de sua mão de obra escrava e tendo sido o último país do novo mundo a abolir seus escravos - é livre de racismo.

Mergulhando na história, mesmo a narrada por apenas um dos lados, nos deparamos com dados e informações que corroboram a compreensão da composição do racismo no Brasil. Mesmo que alguns, entre os milhões de brasileiros insistam em dizer que aqui não há racismo, nossa história pontua o contrário. Os olhares na/para a história nos pontuam eixos através dos quais é possível vivenciar múltiplos olhares, dentre os quais é importante observar o olhar de quem olha e o olhar de quem é olhado.

Na linha dessas ideias, Silva (2009) nos traz dados e informações importantes sobre a escravidão no Brasil. Para o autor: 
[...]40\% do total de nove milhões e quinhentos mil escravos transportados para o Novo Mundo: nove vezes mais que os Estados Unidos (6\%) e bem mais que o dobro da América Hispânica (18\%), do Caribe Inglês (17\%) e do Caribe Francês (17\%). (Silva, 2009, p. 62)

A partir da fala de Silva (2009), constata-se que, no Brasil, ocorreu desde o começo da escravidão, a camuflagem das relações racistas existentes através daquilo a que se convencionou chamar de "jeitinho brasileiro" de dissimular as desigualdades decorrentes de um passado atrelado à escravização de milhões de pessoas. Como saldo desse passado tem-se, atualmente, o que se pode chamar de a cor do trabalho braçal, a cor dos presídios, a cor das vítimas de homicídio e dos que ocupam favelas e os menores níveis de escolaridade.

Dados estatísticos oriundos de pesquisa realizada pelo Instituto Brasileiro de Geografia e Estatística (IBGE) em 2019 com foco nas denominadas Desigualdades Sociais por Cor ou Raça no Brasil, traz dados relacionados à violência, emprego, renda, entre outros, porém o mais comentado na mídia era o que apontava que as quantidades de alunos negros nas universidades públicas representavam $50 \%$ das matrículas, informação que tomou conta do país, foi exibida em telejornais e amplamente divulgada nas redes sociais. Porém, pouco tempo antes dessa notícia, o IBGE divulgou que a população brasileira que se autodeclarava preta ou parda chegava a 55,8\%. Analisando as duas notícias percebe-se que a quantidade de pessoas que estão na universidade ainda não representa a diversidade étnica do Brasil.

Em 2018, no Brasil, os pretos ou pardos passaram a ser 50,3\% dos estudantes de ensino superior da rede pública, porém, como formavam a maioria da população $(55,8 \%)$, permaneceram sub-representados.

Além disso, entre a população preta ou parda de 18 a 24 anos que estudava, o percentual cursando ensino superior aumentou de 2016 (50,5\%) para 2018 (55,6\%), mas ainda ficou abaixo do percentual de brancos da mesma faixa etária $(78,8 \%)$. (AGÊNCIA DE NOTÍCIAS IBGE, 2019)

Voltando aos dados da pesquisa supracitada, eles apontam:
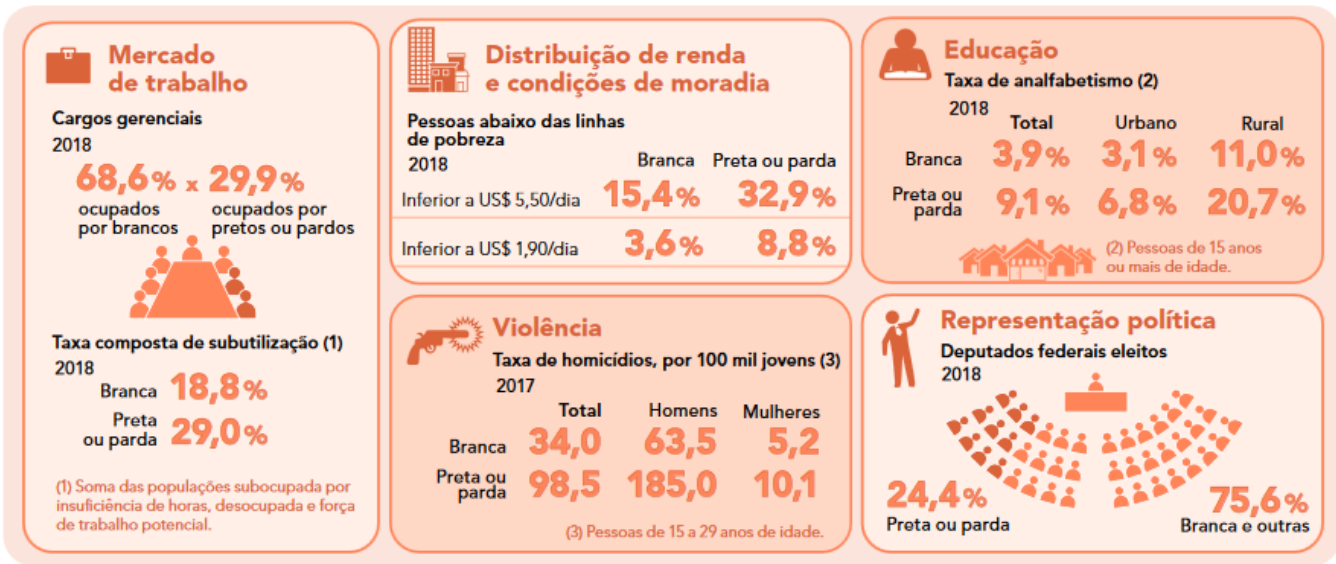

Fonte: IBGE, Desigualdades Sociais por Cor ou Raça no Brasil, 2019 
Assim, por mais que se acreditasse que no Brasil existia racismo, esse era classificado por diversos autores como uma forma menos agressiva. Tal ideia surge a partir de comparação das formas de racismo praticadas no Brasil, denominado "preconceito de marca" com os episódios de apartheid ocorridos nos Estados Unidos e na África do Sul classificados como uma forma extrema de segregação.

[...] Na vã tentativa de inocentar de vez a supremacia branca do latino, a técnica mais usada foi a do confronto histórico, conforme já escrevemos, passando a comparar o preconceito brasileiro com os dos tipos norte-americano e sul-americana, por exemplo. No contexto supracitado, o povo negro, em qualquer interação social diante do branco, é odiado e continua implacavelmente repudiado, na condição de negro ou no 'status' de qualquer 'afro-americano' e 'correlativos'. Fato, que seria bem diferente do sulamericano, estilo à brasileira, porque o preconceito aqui só existiria exclusivamente em seu modelo estético, aparentemente benéfico, já categorizado no ambiente acadêmico como de 'marca'. Quer dizer: a recusa seria somente ao elemento físico, 'à cor', ao fenótipo. A origem estaria salva! É como se a essência do pensamento racista americano e brasileiro, nesse particular, não fosse a mesma, a bem dizer, idêntica, embora perante histórias e formações culturais distintas. (Silva, 2009, p. 58).

Diante dessa situação percebe-se a presença de um racismo dissimulado, travestido de preconceito. Contudo, vemos, ainda hoje, a elite branca dominante escrevendo as linhas da história brasileira e criando uma ideologia que mantém seus postos de poder e dominação da população negra do país. Diante de tanta "harmonia" mesmo saindo de um processo longo de escravização do corpo negro (300 anos) estudos da UNESCO foram realizados com o objetivo de entender como o Brasil tinha um ambiente de harmonia entre as raças. Como resultado, a pesquisa apontou para um tipo de racismo presente no Brasil que difere daquele de outras nações; a essa variação existente aqui, alguns pesquisadores chamam de "racismo à brasileira".

É importante salientar que o racismo, independentemente da forma pela qual se apresenta (voltado para o fenótipo ou genótipo) tem sempre o mesmo fim, ou seja, o extermínio de determinado segmento étnico-racial considerado inferior por questões genéticas, de características físicas e/ou culturais. Tomando as palavras de Silva (2009, p.60) que discorre sobre a letalidade do racismo em qualquer lugar, constata-se que:

Estamos vendo como o racismo - que é toda uma meta de destruição global de um povo - no Brasil, onde mesmo disfarçado de democracia racial, deixando suas mais icônicas características, impondo título a este livro (1985) [racismo à brasileira] também atinge, mesmo lentamente, os seus cruéis objetivos, [...] ainda pelo fato do nosso 'racismo' não ser menos perigoso, nem menos odioso, do que o que é declarado em certos países, pouco importando, portanto, a sua forma disfarçada e hipócrita, nem a académica e oficial alegação de que no Brasil ‘não existiram campos de concentração', pogroms ou 
extermínio premeditado de judeus, índios, negros ou ciganos [...] se o objetivo do racismo 'à brasileira', como já exposto, é o mesmo do racismo americano e sul-africano, por exemplo: destruir e extinguir, inclusive fisicamente, em especial o negro e o judeu [...]. (Carneiro, 1994, p.7).

A partir das palavras de Silva (2009) pode-se perceber que o racismo à brasileira não é menos letal que o racismo encontrado em outros países; no nosso caso, a forma como se dão as relações racistas dentro da sociedade brasileira ocorre de forma engenhosa, sutil, camuflada, bem traiçoeira, fazendo com que a vítima tenha dificuldades de identificá-lo, pois encontra-se presente em todos os segmentos da vida em sociedade. As narrativas contadas conseguem ter um grau de penetração tão grande que quando a população negra percebe que existe uma outra narrativa, uma em que ele não precisa estar na posição mais baixa da pirâmide e que tudo que ele sempre acreditou foi apenas parte de um jogo de manutenção de poder Silva (2019) faz emergir as seguintes perguntas:

O que me impedia de perceber essa realidade? O que me levou a 'naturalizar' a ausência de pessoas negras em escritórios de advocacia, tribunais, parlamentos, cursos de medicina e bancadas de telejornais? O que me levou - ainda que negros e brancos não racistas - a 'normalizar' que pessoas negras sejam a grande maioria em trabalhos precários e insalubres, presídios e morando sob marquises e calçadas? Por que nos causa a impressão de que as coisas estão 'fora do lugar' ou 'invertidas' quando avistamos um morador de rua branco, loiro e de olhos azuis ou nos departamentos com um médico negro? (Silva, 2019, p. 63).

\section{A história e o poder de quem a conta}

Quando nascemos, herdamos uma história pertencente à nossa família, cidade, país e assim por diante. Essa narrativa nos é contada a fim de que tenhamos bases para a construção de nossa história; mas, como são construídas as narrativas às quais temos acesso? Quem conta e constrói essa história? A partir de que olhar e em favor de quem essa história é contada?

Os questionamentos apresentados partem das relações de poder existentes entre dois polos, onde um exerce uma relação de poder sobre o outro, perpetuando-o através da deturpação da imagem e história do grupo dominado, ou seja, o domínio da narrativa de um povo representa poder sobre outro.

Trazendo para as narrativas acerca da população negra no país, Munanga e Gomes (2016) descrevem com maestria os resultados que a narrativa hegemônica trouxe para a imagem e identidade da população negra que por muito tempo foi vista como um povo que não reagiu ao processo de escravidão ao qual foi submetido.

Nessa perspectiva Munanga \& Gomes (2016), salientam que: 
Durante muitos anos, no Brasil, acreditou-se que o africano escravizado sofreu de maneira passiva todos os maus-tratos praticados pelos senhores. Essa crença interferiu e interfere, ainda hoje, no imaginário construído em nossa sociedade a respeito dos nossos antepassados africanos e dos seus descendentes na atualidade: os negros e as negras brasileiras.

É importante que saibamos qual a origem desse tipo de crença e como ela interfere na visão que temos sobre as pessoas negras e no mundo como nos relacionamos com elas. Além de influir em nossas vidas das mais variadas formas, essa visão também tem efeitos na construção da autoestima e da identidade tanto da pessoa negra como das brancas. (p. 67).

Diante do exposto, temos uma noção sobre a história do povo negro no Brasil, vendo que ela é marcada por resistências desde sua chegada. A prova disso são os inúmeros quilombos com extrema organização política, pequenos e grandes levantes contra os senhores e contra decisões de leis. Como exemplo de levantes durante o período de escravidão podemos apontar a Revolta dos Alfaiates (Bahia, 1798), a Cabanagem (Pará, 1835-1840), a Sabinada (Bahia, 1837-1838), a Balaiada (Maranhão, 1838) a Revolta dos Malês (Bahia, 1835) entre outros.

A partir de tantas e tão importantes revoltas para o processo de resistência do povo negro, que iam desde fugas individuais para a formação de quilombos até atentados aos senhores de engenho, o clima de luta pelos direitos resulta em um clima de tensões de forma que,

A relação entre senhores e escravos não era harmoniosa. A sociedade escravista, seja na cidade, seja no campo, não era um lugar calmo e seguro para os senhores e suas famílias e tampouco prevalecia a obediência e a resignação por parte dos escravizados. [...]. Essa era a principal preocupação das autoridades da época e fonte de temores semelhantes aos que eram impostos pelo regime escravista. A manutenção da escravidão torna-se um negócio perigoso e arriscado. (Munanga \& Gomes, 2016, p. 98 e 99)

A partir desses dados, vimos que o poder de contar a história é uma arma poderosa nas mãos de quem detém o poder e para a manutenção do status quo. Para tanto, os grupos ditos superiores criam ideologias tão convincentes que fazem com que haja a subordinação nas relações intergrupais através de uma névoa ideológica.

Para a perpetuação do poder, os dominados devem ver como certa/natural as relações existentes nos âmbitos da sociedade tais como gênero, classe, raça - entre outros -, reproduzindo exatamente o que é de interesse da classe dominante.

Nas relações entre negros e brancos, que é o nosso foco, também ocorrem as relações de poder e dominação de forma que o negro é envolvido no que Chimamanda Ngozi Adichie, uma escritora nigeriana, chama de "o perigo de uma única história". Em uma fala no TED 
Colocar o que é TED em 2009, Chimamanda conta sobre como ela foi vítima de uma história única, na qual acreditou por muito tempo e como outras pessoas também acreditavam em uma história única sobre a África.

Como Chimamanda uma grande maioria da população negra também acredita em uma história única que tende a naturalizar as desigualdades e segregação negativa da população negra. No caso dos negros brasileiros, a história única contada pela supremacia branca é a de que vivemos em uma democracia racial e que não existe racismo no Brasil. Sem estarmos acordados dessa história única, o negro brasileiro passa toda sua vida sem ao menos perceber que as desigualdades baseadas na raça o atinge, visto a dissimulação sob a qual esse racismo acontece.

\section{Considerações finais}

Diante das discussões já realizadas até aqui e ciente de que as questões raciais no Brasil e no mundo compreendem um assunto de grande magnitude para ser esgotado em um artigo, podemos concluir que a história do negro foi narrada por muito tempo partindo do dualismo Branco/Negro onde o primeiro grupo criou narrativas que pudessem justificar a dominação do segundo.

Inicialmente o estranhamento pelo fenótipo e, mais tarde, a justificativa científica que deu força à dominação de índios e negros no continente americano deixaram cunhados em nossa história resultados que até hoje reverberam na forma de ver o negro e o índio. Ambos os povos foram destituídos da condição de humanidade e lutam até hoje por direitos básicos e por equidade em todos os espaços da sociedade.

Em meio a avanços e retrocessos, esses segmentos étnicos continuam resistentes na busca por melhores condições, respeito e principalmente tentando mudar o imaginário de um país racista quanto à imagem dos negros que outrora foram descritos como degenerados, malandros, pouco inteligentes etc. buscando também - através dessa reescrita de suas histórias - quebrar dentro dos próprios negros o estereótipo ruim no qual essa sociedade os fez acreditar. 


\section{Referências}

Almida, S.L. (2019). Racismo estrutural. São Paulo: Pólen.

Camargo, Oswaldo de; Colina, Paulo \& Rodrigues, Abelardo (1986). Razão da chama: antologia de poetas negros brasileiros. São Paulo: GRD.

Chimamanda. N. A. (2020). O perigo de uma única história. Disponível em: $<$ https://www2.ifmg.edu.br/governadorvaladares/noticias/adelia-a-poesia-e-a-vidaconvite-para-o-3o-encontro-do-dialogos/o-perigo-de-uma-historia-unica-chimamanda-ngoziadichie-pdf.pdf>. Acesso em: 12 de fev.

Dicionário Priberam da Língua Portuguesa (2020). Disponível em $<$ https://dicionario.priberam.org/etnia> Consultado em 11-02-2020.

IBGE (2010). Desigualdades Sociais por Cor ou Raça no Brasil. Disponível em: <https://biblioteca.ibge.gov.br/visualizacao/livros/liv101681_informativo.pdf>. Acesso em: 10 de jan. 2020.

Firmino, D; Domênico, D; Oliveira, R; et al.(2019). História Pra Ninar Gente Grande. Rio de Janeiro: Mangueira.

Silveira, O. (1986). Treze de maio Disponível em: $<$ http://www.letras.ufmg.br/literafro/autoras/11-textos-dos-autores/848-oliveira-silveira-trezede-maio>. Acesso em 10 jan. 2020.

Silva, M. J. (2009). Racismo à brasileira: raízes históricas: um novo nível de reflexão sobre a história social do Brasil. 4. ed. São Paulo: Anita Garibaldi, 2009.

Munanga, M \& Gomes, N. L. (2016). O negro no Brasil de hoje. 2.ed. São Paulo: Global, 2016.

\section{How to cite this article (APA format):}

Santana, Lousana de Jesus; Purificação, Marcelo Máximo; Catarino, Elisângela Maura; Ferreira, Denilra Mendes; Bessa, Akira de Alencar Borges (2020). Child Bedtime History For Grown Up People: Race, Racism And Power In Brazilian History. Am. In. Mult. J., Jul to Oct. (9) 5, 205-215.

Received: 10/01/2020;

Accepted: 10/05/2020. 